\title{
The cultural context of biological adaptation to high elevation Tibet
}

\author{
Loukas Barton \\ University of Pittsburgh, United States
}

\section{A R T I C L E I N F O}

\section{Article history:}

Received 16 October 2015

Received in revised form 16 December 2015

Accepted 11 January 2016

Available online 27 January 2016

\section{Keywords:}

Tibet

Adaptation

Hypoxia

Agriculture

Selection

Gene-culture co-evolution

\begin{abstract}
A B S T R A C T
Permanent, year-round occupation of high elevation, low oxygen environments is next to impossible for human populations adapted to low elevation, high oxygen environments. Sustained human habitation of high elevation environments is therefore a comparatively late development in global human history. Though we are beginning to understand the biological differences between contemporary highland and lowland populations, we do not understand how, or when, these differences evolved. This paper presents a hypothesis for the historical context of human adaptation to the Tibetan Plateau. Archaeological data suggest that Neolithic agricultural groups living on the northeast margins of the Plateau expanded to the altitudinal limits of their farming systems by 5200 cal BP, but also to the limits of human physiological capacity for high elevation (at $2500 \mathrm{~m}$ above sea level). With the introduction of novel, exotic domesticates (namely barley, wheat, and sheep), Neolithic agriculturalists started to push these limits, and in roughly 1600 years (by 3600 cal BP) small groups of people were living at higher elevations and deeper into the Tibetan Plateau. This required and encouraged novel cultural solutions to high elevation settings, but also imposed heavy selective pressure on the physiological capacity for low oxygen environments. These new cultural capacities enabled people to move into a stronger environment of selection (above $2500 \mathrm{~m}$ above sea level) that favored the physiological capacities for life at high elevation, which in turn became more common across these populations. This hypothesis about bio-cultural evolution is testable with a combination of high-resolution archaeological evidence and high throughput sequencing of datable prehistoric human DNA.

(C) 2016 Elsevier Ltd. All rights reserved.
\end{abstract}

\section{Background}

Sustained human occupation of high-elevation settings $(>2500 \text { masl })^{1}$ requires biological and cultural adaptation to a range of environmental factors including reduced ambient oxygen pressure, strong ultraviolet radiation, limited plant and animal resources, time compressed biotic productivity and pronounced seasonality, and volatile, unpredictable patterns of temperature and precipitation (see Aldenderfer, 2006). The history of human life on the Tibetan Plateau, for example, must be understood in light of these factors and remains an active field of inquiry for archaeologists, paleogeographers, linguists and biologists alike (Aldenderfer and Zhang, 2004; Brantingham and Gao, 2006; Brantingham et al., 2003, 2007, 2013; Chen et al., 2015; d'Alpoim Guedes, 2015; d'Alpoim Guedes et al., 2013; Miehe et al., 2009, 2014; Peng et al., 2011; Qi et al., 2013; van Driem, 2005; Zhao et al., 2009 and all of the papers in this Special Issue).

An important question is whether or not the constraints of elevation on physiological performance mitigated against the human occupation of the Tibetan Plateau. If so, we want to know when, and ultimately how human physiology evolved to meet these constraints, and we

\footnotetext{
${ }^{1}$ Here we follow Bigham and Lee (2014) in defining high elevation environments as anything above $2500 \mathrm{~m}$ above sea level (masl), at which point oxygen saturation of hemoglobin begins to fall in most humans (also see Niermeyer et al., 2001).
}

want to understand why it took as long as it did. We know that people (of some kind) lived in the lower elevation areas adjacent to Tibet by at least 80,000 years ago, ${ }^{2}$ and likely much earlier (Bettinger et al., 2010a; Morgan et al., 2011), yet the earliest archaeological evidence for people in Tibet dates somewhere from 20,000-15,000 years ago (Brantingham et al., 2013; Zhang and Li, 2002). Furthermore, sedentary (or at least semi-sedentary) low-level agriculturalists appear adjacent to the Plateau by roughly 7900 years ago, with full-blown sedentary farming in place by 6200 years ago (Barton, 2009; Barton et al., 2009b) whereas significant numbers of people do not live on the Plateau until after 4000 years ago (Chen et al., 2015; d'Alpoim Guedes, 2013, 2015). The timing of sustained, year-round occupation of the Tibetan Plateau is a subject of considerable debate, addressed by nearly every paper in this Special Issue. Through a combination of archaeological data like these, inference from the human genome, evidence for human impacts to high elevation ecosystems, and a theoretically informed approach to understanding the interactions among each of these things, we will ultimately identify population-level processes that made it possible for people to live high up on the Tibetan Plateau throughout the year.

Though I recognize that our understanding of the physiological processes that make year-round life possible and productive at high

\footnotetext{
${ }^{2}$ All dates provided herein are calendar years before present (cal BP).
} 
elevation is rapidly improving (e.g. Simonson, 2015), that this suite of physiological attributes differs in different parts of the world (e.g. Beall, 2007), and that some of the molecular foundations for at least some of these adaptations may pre-date permanent life at high elevation (e.g. Huerta-Sanchez et al., 2014), I also suggest this is a fruitful opportunity for hypothesis building. Now that the archaeology of the Tibetan Plateau is improving rapidly, and our ability to sequence vast portions of the nuclear genome from ancient human remains reliably is an increasing reality (see Raghavan et al., 2014; Rasmussen et al., 2014, 2015), such hypotheses will help to stimulate further research. This is the spirit in which this Special Issue on the Peopling of Tibet was organized.

This essay provides a hypothesis about the context of physiological adaptation to high elevation environments, based on archaeological data surrounding the Tibetan Plateau. Here I aim to establish the cultural and historical environment of selection that might have made such adaptations common among groups of inter-connected people who eventually colonized the high plateau successfully and permanently.

\section{Physiology at high elevation}

Organisms unaccustomed to the declines in barometric pressure and absolute concentration of oxygen associated with increasing elevation experience a variety of physiological and reproductive challenges largely associated with hypoxia - generally, an inadequate supply of oxygen in the blood (Bigham and Lee, 2014; Niermeyer et al., 1995, 2001). In humans, chronic hypoxia has been linked to individual manifestations of heart disease, stroke, anemia, pulmonary hyptertension, low birthweight and infant mortality that carry population-level consequences (excellent recent reviews include: Beall, 2013; Bigham and Lee, 2014; Scheinfeldt and Tishkoff, 2013; Simonson, 2015). As with other organisms (see Storz et al., 2010, 2013), several human populations have developed geographically distinct, and genetically-based pulmonary, hematological and/or vascular adaptations to low-oxygen environments (Beall, 2007; Hornbein and Schoene, 2001; Scheinfeldt and Tishkoff, 2013; Simonson et al., 2012). Genome-wide analyses of contemporary Tibetan populations, for example, suggest that the genetic foundations for at least some of these adaptations were under strong directional selection, a likely testament to the fitness benefits associated with them (Beall et al., 2004, 2010; Bigham et al., 2010; Peng et al., 2011; Simonson et al., 2010; Wang et al., 2011; Xu et al., 2011; Yi et al., 2010). Exactly how these genetic changes produced fitnessenhancing adaptations is uncertain and is the subject of very active research, yet it seems increasingly likely that the physiological adaptations to hypoxia result from multiple gene interactions (Bigham and Lee, 2014). One thing revealed in the genetics of Tibetan populations is that there are numerous adaptations to explain, among them tolerances for different environmental and atmospheric contexts. Furthermore, a variety of genetic analyses suggest that natural selection for adaptations to high-elevation hypoxia is ongoing in contemporary Tibetan populations (Beall, 2007).

\section{Tibetan origins}

Efforts to understand the genesis of Tibetan people, heritage, culture, and identity, are diverse. Those tuned to the early history of Tibet focus on two distinct angles: 1) the molecular (e.g. Qi et al., 2013; Qian et al., 2000; Su et al., 2000; Torroni et al., 1994; Wang et al., 2011; Zhao et al., 2009) and linguistic (e.g. Sagart, 2005; van Driem, 2002, 2005) ancestry of people who currently identify as "Tibetan" (broadly construed); and 2 ) the antiquity of a human presence in a high-elevation geographic province called the Tibetan Plateau (Aldenderfer, 2006; Aldenderfer and Zhang, 2004; Brantingham and Gao, 2006; Brantingham et al., 2001, 2003, 2007, 2013; Huang, 1994; Tang and Hare, 1995; Tong, 1985; Zhang and Li, 2002). On their own, neither of these things tells us very much about the evolutionary process that makes contemporary highlanders biologically distinct (they are merely parts of the story). Yet this process of relatively recent biological adaptation provides important insights about the nature of evolution under selection, and expands our ability to track gene-culture co-evolution in more complex geneenvironment interaction systems.

Molecular phylogeographies have been used to track the movements of people (namely those who today identify with Tibet) from geographic points of origin, as well as the genetic underpinnings of physiological adaptations to high elevation. Much of the debate is really about where (or from whom) the Tibetan people came and how long ago they went their separate ways. Recent reports differ on the strength of the historical relationships between contemporary Tibetans and people currently living in different parts of Asia; essentially, current interpretations of the molecular evidence for the history of these people are conflicted, contradictory, and uncertain (for an excellent summary see Rhode, 2016-in this issue). Our understanding of this molecular history will change dramatically, hopefully with greater clarity, in the coming years.

Furthermore (and unfortunately), the chronology for much of this story is only beginning to emerge, and estimates often conflict. Chronologies based on molecular coalescence estimates alone suggest that the divergence of contemporary Tibetan populations, the emergence of physiological adaptations to oxygen deprivation, and therefore persistent human occupation of the Tibetan Plateau, range from approximately $30,000 \mathrm{BP}$ to little more than $3000 \mathrm{BP}$.

Some geneticists suggest that contemporary Tibetans may have first moved to the Plateau during the late Pleistocene (Qi et al., 2013; Zhao et al., 2009). Yet the bulk of the studies using molecular data suggest that contemporary Tibetans moved, in number, to the Plateau at some point during the Neolithic (Qi et al., 2013; Wang et al., 2011; Zhao et al., 2009). If true, both inferences seem reasonable: though small populations of people may have lived on the Tibetan Plateau during the late Pleistocene, they were later over-run by increasing numbers from somewhere else. But the dating remains equivocal. One has to wonder just how much of this molecular age estimation is informed by an archaeological record that can barely speak for itself with any confidence.

Recently, one hypoxia pathway gene (called EPAS1) present at relatively high frequency in modern Tibetan populations was identified in a fossil finger bone from Denisova Cave in the Siberian Altai (HuertaSanchez et al., 2014). If the context and dating of the element are correct, this finding suggests that at least one person on earth possessed at least some of the genetic underpinnings of at least one adaptation to hypoxia, approximately 50,000 years ago. This is of course interesting, and the authors suggest many contemporary Tibetan people possess this gene because of an ancestral pattern of introgression. However the antiquity of this gene says little about population-level adaptations, and does not confirm that the Denisovans were capable of life at high elevation. Furthermore, neither the antiquity of this hypoxia pathway gene nor the evidence for inter-specific introgression says anything about the environment of selection that made it common in modern Tibetans (or anyone else), or when this might have happened.

Though many geneticists acknowledge that coalescence-based ageestimates are problematic, the enormous variance in these estimates makes it impossible to track the process of adaptation to highelevation environments in light of emerging cultural and environmental contexts of natural selection. Beyond the historical time-line of physiological adaptations, we also need to be able to explain how cultural behaviors (including adaptations to cold stress, and resource risk and uncertainty) evolved to meet the demands of higher elevations. The archaeology of the Tibetan Plateau and surrounding regions provides a baseline for addressing these issues.

\section{Early human activity on the Tibetan Plateau}

While there is some indication of ephemeral human activity on the central Tibetan Plateau during the Last Glacial Maximum, ca. 20,000 BP (Zhang and Li, 2002), the earliest firm evidence for human presence 
on the northeast Tibetan Plateau dates from approximately 15,00012,000 BP (Brantingham et al., 2013). These early forays on the Plateau were likely limited to occasional expeditions to access large game, and the pattern seems to expand to long-distance seasonal movements to higher elevations, from 8000 to $6000 \mathrm{BP}$ (Brantingham and Gao, 2006; Brantingham et al., 2013). The nature of these post-Glacial and early Holocene hunter-gatherer activities is only beginning to come to light (Brantingham and Gao, 2006; Brantingham et al., 2013; Madsen, 2016-in this issue; Madsen et al., 2006; Rhode, 2016-in this issue; Rhode et al., 2007b) but the primary issue here is whether or not this early human presence reflects adaptations sufficient to permit permanent and extensive year-round survival and reproduction in marginal high-elevation environments.

On the face of it, there is no reason to believe that human foragers were any less technologically or organizationally capable of permanent life on the Tibetan Plateau than they were capable of life on the Chinese Loess Plateau to the northeast, or much further north, into the Altai Mountains, the Baikal Rift, or Siberian Beringia. Certainly, if the Denisovan genome truly reveals the capacity for managing hypoxia (and I'm skeptical that it does), then any modern descendants of these Altai Mountain peoples might have also had the physiological ability to thrive at high elevation in Tibet. Assuming hypoxia was not an issue for at least some groups of people within striking distance of the Tibetan Plateau during the late Pleistocene and early Holocene, what would it take for them to survive in such an environment? Highly adapted tool kits, the capacity for fire making, high quality clothing, winter mobility, storage, coordinated organizational procedures for marriage, alliance, and sharing have all been implicated in the successful occupation of marginal, resource-poor, highly seasonal environments throughout northern Eurasia (Barton et al., 2007; Elston and Brantingham, 2002; Elston et al., 2011; Goebel, 1999; Hoffecker, 2005; Madsen, 2016-in this issue; Rhode, 2016-in this issue; Yi et al., 2013), and in Andean South America (Aldenderfer 1998, 2003, 2004). Unfortunately, the archaeology of the Tibetan Plateau during this period is silent on most of these issues. Hunter-gatherer archaeology of the late Pleistocene and early Holocene of Tibet and its surroundings demands a lot more attention.

More recently, considerable evidence for the Late Neolithic occupation of Tibet (broadly construed as a sedentary, pottery producing, agricultural pattern, ca. 6000-4,500 BP) has come forward. Recent work on the northeastern portion of the Tibetan Plateau, in Qinghai and Gansu provinces, outlines a pattern of population expansion up the Yellow River that eventually expands to higher elevation after an extended pause around 2500 masl, ca. 5200-3,600 BP (Chen et al., 2015). Similarly, the presence of Late Neolithic settlements in the highlands of western Sichuan has come into much sharper focus (Chen, 2007; Chen et al., 2004; d'Alpoim Guedes, 2013; Hein, 2015; Jiang, 2007; Liu and Wei, 1974; Xizang and Sichuan, 1985) though the nature of the economic and social life of these people has not yet been thoroughly explored (d'Alpoim Guedes, 2015). That said, recent archaeobotanical sampling and analyses have begun to reveal patterns of plant use throughout the region that hold promise for explaining the nature of highelevation habitation, and the role of cultivation, transport, and trade in it (d'Alpoim Guedes et al., 2013, 2015). Likewise, agro-ecological models that identify areas amenable for productive cultivation enable critical evaluation and interpretation of the archaeological record (Barton, 2014; d'Alpoim Guedes, 2013, 2015; d'Alpoim Guedes and Butler, 2014; d'Alpoim Guedes et al., 2015). More current results of recent research can be found in each of the other papers in this Special Issue. The point is that our ability to generate ideas about the peopling of the Tibetan Plateau, and to then test those ideas against an increasingly detailed archaeological record are both improving by leaps and bounds.

\section{Adaptation to life in high elevation environments}

Physiological adaptations to oxygen deficiency are often considered requisite for successful human colonization of the Tibetan Plateau. In the absence of physiological adaptations to low oxygen environments, far more energy is required to support a human basal metabolic rate (BMR) at high elevation than at sea level (Beall, 2007). Maintenance of BMR at high elevations limits availability of energy for other tasks such as physical activity, growth, and reproduction. This is one reason why fecundity is low and infant mortality high for low-landers living at high elevation (Beall et al., 2004), and illustrates how permanent, year-round, multi-generational occupation of the Tibetan Plateau might be difficult to sustain in the absence of physiological adaptations to hypoxia. However, it is insufficient to suggest that successful occupation of high elevation environments rests on human biology alone (c.f. Beall, 2007). The logic of using different agricultural products at different elevations is also important to the process of adaptation to high elevations. Indeed, the ability to provide food year-round, and to minimize variance in food production and therefore food availability may be just as important to stable and permanent human occupation of high elevation zones as physiological adaptations to oxygen deficiency or cold weather.

People have cultivated millet in the lowlands just east of Tibet for at least 7900 years (Barton, 2009; Bettinger et al., 2010b), but the commitment to and dependence upon agricultural products in these lowland areas increased dramatically after 6200 BP (Barton et al., 2009b). Data from the northeast Tibetan Plateau and adjacent areas to the east (Chen et al., 2015) reveal a westward, and upward expansion of this millet-farming system to 2500 masl by 5200 BP. Expansion further upslope is limited on the one hand, by the energetic limitations of hypoxia above 2500 masl, but also by the instability and unpredictability of millet-based agriculture. Because they grow and ripen quickly and require little water, millets are well suited to a variety of farming strategies in arid and upland northwest China. Indeed, these attributes have been implicated in both the initial adoption of millet by mobile hunter-gatherers (Barton et al., 2009a; Bettinger et al., 2010b), and the diffusion of agricultural subsistence to some lower-latitude highland environments (d'Alpoim Guedes et al., 2013). Yet millets are poorly suited to the higher elevation conditions of the Tibetan Plateau.

As with most plants, the thermal requirements of millet germination and growth dictate where it can thrive and where it cannot (Anderson, 1994; d'Alpoim Guedes, 2013; Kamkar et al., 2006). Late Neolithic farmers living along the eastern margins of the Tibetan Plateau would have faced increasing inter-annual variability in millet harvest yields with increasing elevation. Western domesticates - specifically barley however, are much less susceptible to low and freezing temperatures, and therefore harvest yields are less variable at higher elevations (d'Alpoim Guedes, 2013; d'Alpoim Guedes and Butler, 2014; d'Alpoim Guedes et al., 2013, 2015).

The initial adoption of barley, and to a lesser degree wheat, may have helped millet-farmers on the eastern margin of the Tibetan Plateau just below 2500 masl to buffer the shortfalls of meager or failed harvests during anomalously cold years near the altitudinal limits of millet harvest predictability. Expansion to higher elevations was possible only by shifting emphasis to cultivars less sensitive to variations in temperature stress. In various ways, this scenario has been argued for different portions of an $800 \mathrm{~km}$ stretch along the eastern margin of the Tibetan plateau, from north (e.g. Chen et al., 2015) to south (e.g. d'Alpoim Guedes et al., 2015). Presumably, the entire pattern of risk reduction would have been further enhanced by adding Western animal domesticates - specifically sheep and perhaps cattle - to the high elevation subsistence portfolio, a practice that likely also added to the abundance of fuel (dung) in an otherwise fuel-poor environment (Rhode et al., 2007a). And this seems to be so: sheep were added to the subsistence portfolio of people living above 2500 masl after $3600 \mathrm{BP}$, at least in the northeastern part of the Plateau (Chen et al., 2015).

\section{Demographic expansion towards higher elevation habitats}

Archaeologists who study human use of high elevation environments (even those below the 2500 masl limit) typically suggest that 
intensive occupation is a relatively late phenomenon (Bettinger, 1991; Morgan et al., 2012; Neme, in press). The argument is that life at high elevation is difficult for a variety of reasons, and unlikely to happen unless competition for lower elevation settings and resources becomes exceedingly high (or at least equivalent to those of higher elevations). Key to each of these arguments is that population growth in the lowlands (and the declines in per capita efficiency and productivity that come with it) pushed people into the highlands.

Previous authors (Brantingham et al., 2007) have proposed that the earliest expansion of low-level farmers in the Western Loess Plateau might have pushed neighboring non-agricultural people into higher elevations around $8000 \mathrm{BP}$, and this seems to accord with the increase in evidence for human foragers on the Tibetan Plateau (Brantingham et al., 2013), as well as with the evidence for abrupt increases in human impacts to the Plateau ecosystem (Miehe et al., 2009). Yet there is little direct evidence for intensive, permanent human occupation of the northeastern margin of the Plateau for another 2800 years, or anything above 2500 masl for another 4400 years (by $~ 5200 \mathrm{BP}$ and $\sim 3600 \mathrm{BP}$ respectively, see Chen et al., 2015). I suspect the initial lag of 2800 years has more to do with Late Neolithic demographic processes unfolding on the Loess Plateau than it does with the habitability of the high elevation Tibetan Plateau (which is an issue that surrounds the latter 4400 year time lag before people move up to higher elevation).

Observations based on provincial cultural resource archives (e.g. Guojia Wenwuju, 2011) complemented by semi-systematic radiocarbon dating of known sites (Chen et al., 2015) point to a westward expansion of the Yangshao Neolithic agricultural complex by $5900 \mathrm{BP}$, concomitant with the appearance of a fully intensive millet-based agricultural system in the region (Barton, 2009; Barton et al., 2009b). Several authors (An et al., 2004, 2005; Barton, 2009) have used evidence for change in the abundance and distribution of archaeological sites from ca. 6000 to $3000 \mathrm{BP}$ to point to increases in the absolute numbers of people in the region, and to a westward (and upward) shift in the core areas of occupation intensity. Certainly the interpretation of such data can be problematic, and perhaps more intensive systematic regional archaeological survey would help to settle the issue (Drennan et al., 2015). Yet on the basis of existing information gathered over a fairly large area, I'm willing to suggest that this westward and upward movement was likely a result of demographic stress in the agricultural heartland: moving was simply less costly than learning to cope with larger populations competing for limited farmland. Soon people were living everywhere that millet farming was feasible. Importantly, the upper altitudinal limits of that feasibility seemed to be set at about 2500 masl. Archaeological data from the northeastern Tibetan Plateau (Chen et al., 2015) suggest that the appearance of large, presumably permanent human settlements above 2500 masl after 3600 BP was accompanied by exotic domesticates (barley, wheat, and sheep) introduced from the west, leading the authors to suggest that those plants and animals made it possible for humans to live at higher elevations. Did these groups possess the physiological adaptations for life at high elevation? If so, did their Neolithic predecessors living below 2500 masl possess them as well, or did they evolve somewhere along the way?

\section{Hypothesis about the evolution of physiological adaptations to hypoxia}

Demographic packing along the 2500 masl margin of the eastern Tibetan Plateau, which began by 5900 BP but increased dramatically by 5200 BP (Chen et al., 2015), demonstrates that the late Neolithic populations of the region did not possess the requisite cultural or biological solutions to life at higher elevation, but by at least $3600 \mathrm{BP}$ the process of adaptation was well underway. Because barley and wheat were both known to the people of the region by at least $4500 \mathrm{BP}$ (An et al., 2013; Barton and An, 2014; Chen et al., 2015; Dodson et al., 2013; Flad et al., 2010; Li and Mo, 2004; Li et al., 2007a, 2007b), and domesticated sheep were known a bit further afield by at least $5700 \mathrm{BP}$ (Dodson et al.,
2014), it's unlikely that the presence of these things alone made it possible for large numbers of people to survive and reproduce at higher elevation.

Here I suggest that the process of cultural and biological adaptation happened in two critical phases (See Fig. 1 for a schematic illustration). First, from at least 5200 BP to about 3600 BP large, sedentary, stable populations lived astride the altitudinal limits of their ability to cope with the initial complications of hypoxia but also the limits of predictable millet-based agriculture. During this time, certainly some people attempted to move up in elevation, driven by the same demographic pressures that pushed their predecessors up the river valleys and foothills to 2500 masl. The archaeological record however suggests these efforts above 2500 masl were largely unsuccessful, even though their neighbors at and below this margin had learned to thrive. Occasional evidence for the use of agricultural products high on the Plateau might be examples of these early, short-lived forays (e.g. Hou et al., 2016-in this issue). Since during this time most people lived below the elevation where hypoxia begins to affect survival and reproduction, the environment of biological selection was relatively weak. Still, it is possible that this relatively weak selection began to act on the physiological capacity to tolerate hypoxia, perhaps leading to marginal increases in gene frequencies across some groups. Furthermore, during this time people began to experiment with novel agricultural products, fine-tuning their production to the local environment, and with them buffering the occasional shortfalls of the millet harvest.

In the second phase (fully in place by $3600 \mathrm{BP}$ ), demographic stress pushed people into higher elevations (perhaps up to and even beyond 3500 masl) where the effects of hypoxia were even more severe. This time, however, they brought the new products with them: sheep to convert the otherwise inedible high-elevation vegetation into calories people could eat, and both barley and wheat that could be cultivated and stored with at least some predictability. Basically, these new agricultural products enabled people to live, albeit tenuously, in an environment to which they were otherwise poorly suited.

It was in this environment that selection had a significant effect on gene frequencies, and the genetic underpinnings of the physiological adaptations to hypoxia became increasingly common. The nature of this selective sweep would be fertile ground for modeling in population genetics. I suggest this selective sweep was unlikely to proceed at lower elevations (where selection would have been weak) and unlikely to happen at even higher elevations (where persistent and sustainable human life in large groups was untenable). Introduction of agricultural products suitable to high-elevation environments may have been essential to the environment of selection that led to the evolution of physiological adaptations to hypoxia, first because it made life along the altitudinal margin of 2500 masl more secure, and later because it made life at even higher elevations possible.

In summary, even though culture (plant and animal domesticates, food storage, etc.) made it easier to live above 2500 masl, life was still tenuous. Basically these cultural traits enabled people to move into a stronger environment of selection where physiological capacities for mitigating hypoxia became more common. Though this process probably began ca. 5200 BP it accelerated sometime before 3600 BP when new plants and animals enabled people to move into environments less suitable to human survival and reproduction. By $3600 \mathrm{BP}$ people were living well beyond 2500 masl, under a subsistence regime dominated by barley, wheat, and sheep (Chen et al., 2015).

Here it is important to mention that several contentious issues raised in the literature are irrelevant to this hypothesis. First, whether or not people cultivated barley, wheat (or anything else) above 4000 masl is an interesting question relevant to many historical patterns on the Tibetan Plateau; but it doesn't factor in the current hypothesis. Likewise, whether or not the presence of barley and/or wheat above 2500 masl reflects local cultivation, transport, or trade is also an interesting question, and worthy of continuing investigation, but all that really matters to the current hypothesis is that people were able to produce these staples 
A.

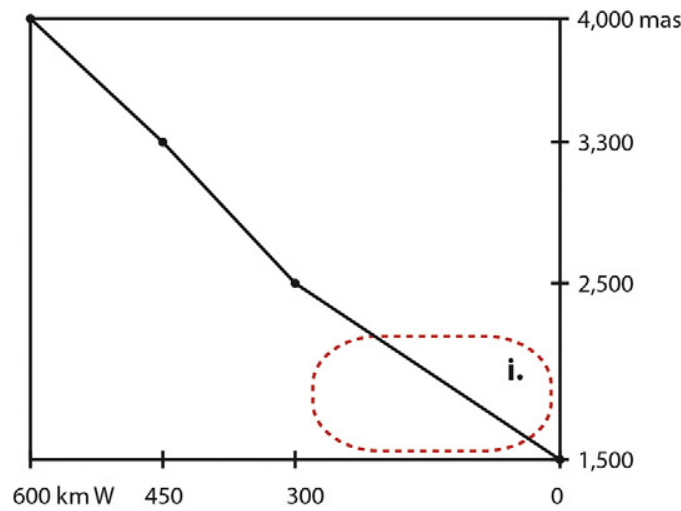

C.

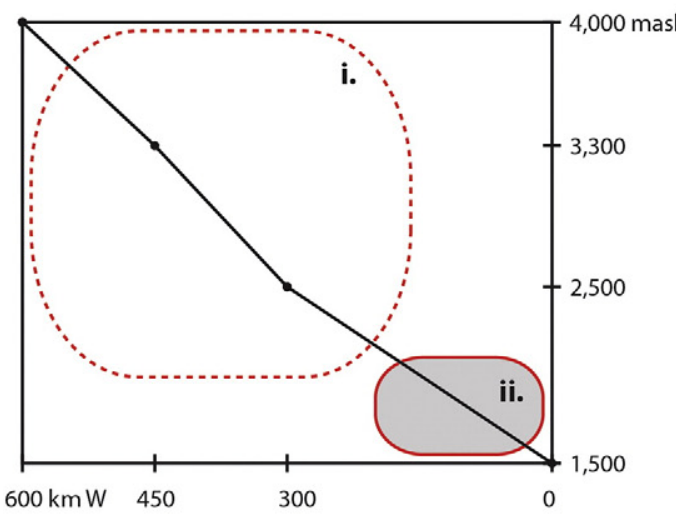

E.

3,600 cal BP

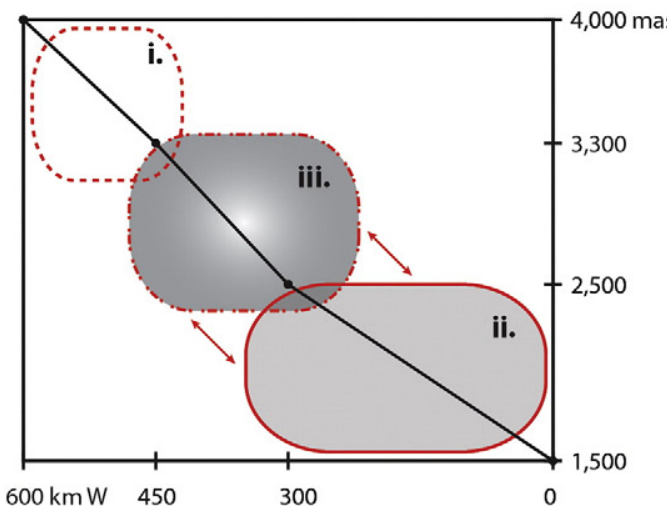

B. $<15,000$ cal BP

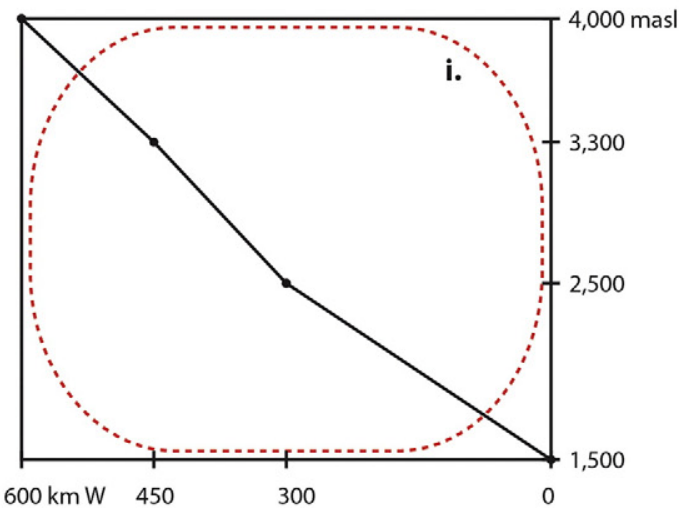

D. $5,200 \mathrm{cal} \mathrm{BP}$

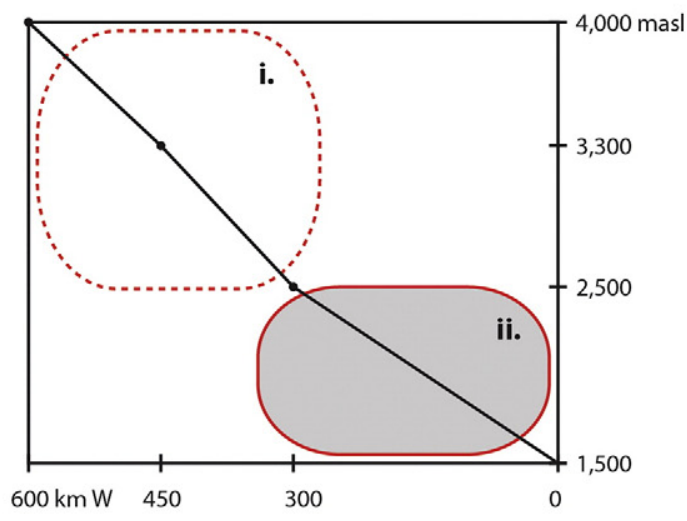

F. $<3,600$ cal BP

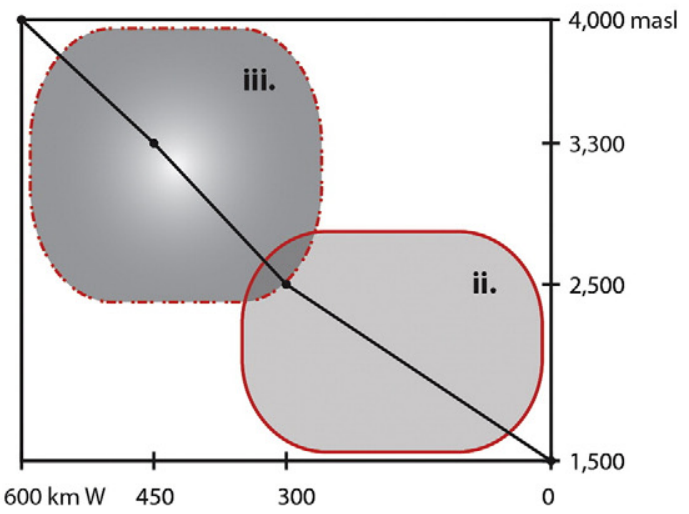

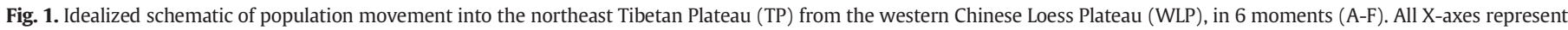

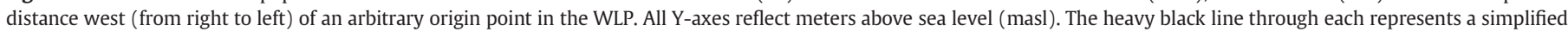

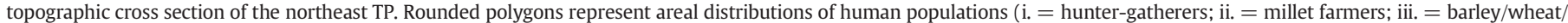

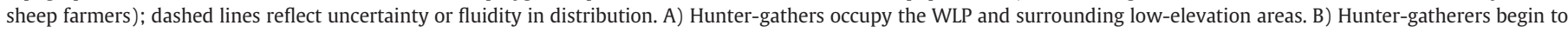

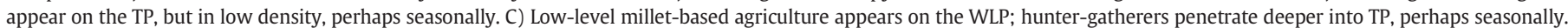

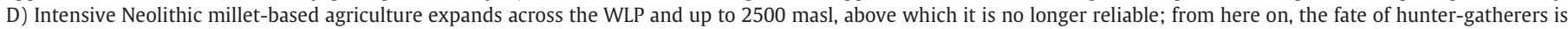

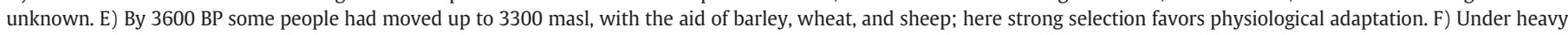
selection at increasing elevation, highlanders become biologically distinct from lowlanders.

reliably and predictably below 2500 masl. This hypothesis is entirely about the presence of large numbers of people at the altitudinal limit, and the potential this proximity to higher elevations has for increasing population-wide frequencies of the physiological adaptations to hypoxia.

Furthermore, this hypothesis emerges from current observations about the prehistory and biology of people living on the Tibetan Plateau. In light of the evidence, this seems the most likely scenario for human adaptation enabling sustained occupation of high elevation ecosystems, and it begs further testing. Similarly, alternative explanations, including those suggesting that human capacities for life at high elevation evolved much earlier (e.g. Aldenderfer, 2007; Madsen, 2016-in this issue; Rhode, 2016-in this issue), as well as those that posit completely different source areas than the one proposed here (e.g. Hazarika, 2016-in this issue; Lu, 2016-in this issue), also demand consideration, and detailed testing.

In addition to the timing, location, and direction of human population movement to higher elevations, and the presence (or absence) of 
specific plant and animal products in different times and places, a number of other issues relevant to the cultural and historical environment of selection are beginning to appear in the literature. Among them are debates about whether or not the early evidence for agricultural products on the Plateau was a result of local production or long distance trade, and whether or not the presence of agricultural products points to symbiotic interdependence between foragers and farmers, or between herders and farmers (see d'Alpoim Guedes, 2015; Madsen et al., 2006; Rhode et al., 2007b and several papers in this Special Issue).

Ultimately, resolution of these issues will be crucial to understanding how people were able to inhabit and thrive on the highest plateau in the world. We aren't there yet, and more work must be done. In an ideal world, archaeological investigation in Tibet would be open to a greater number of researchers, with different backgrounds, different interests, and different expertise. This diversity would infuse the research field with many new ideas, testable through rigorous field and laboratory study, and make it increasingly possible to understand the nature of both local historical process, and the scale and scope of human biocultural evolution (also see Rhode, in this issue).

\section{Conclusion}

Archaeological data reveal the patterns of human movement to the Tibetan Plateau, and in so doing provide insight on the process of biological adaptation to high elevation environments. It is important to understand and explain the processes of cultural adaptation (e.g. the adoption and modification of Western domesticates), but the archaeological data will also set the boundaries for understanding biological evolution. Most critical to this is an understanding of the pattern and tempo of demographic change in relation to the environment of selection. In tandem with modeling in population genetics, archaeological data on the spatial and temporal distribution of human fecundity and mortality will help to explain population-level change in physiological solutions to hypoxia, and the role that cultural factors such as high-elevation agriculture played in the process of biological evolution. If the hypothesis presented herein stands up to further testing, this would be an important example of gene-culture co-evolution (e.g. Richerson et al., 2010) where reciprocal change in both cultural practice and gene frequency leads to significant geographic differences among human populations. I hope this framework invites continuing exploration of modeled approaches to both modern and ancient DNA, as well as detailed regional analysis of the archaeological patterns of human demography, subsistence, and interaction.

\section{References}

Aldenderfer, M., 1998. Montane Foragers: Asana and the South-Central Andean Archaic. University of Iowa Press, Iowa City, IA.

Aldenderfer, M., 2006. Modelling plateau peoples: the early human use of the world's high Plateaux. World Archaeol. 38, 357-370.

Aldenderfer, M., 2007. Modeling the Neolithic on the Tibetan Plateau. In: Madsen, D.B., Gao, X., Chen, F.H. (Eds.), Late Quaternary Climate Change and Human Adaptation in Arid China. Elsevier, Amsterdam, pp. 151-165.

Aldenderfer, M., Zhang, Y., 2004. The prehistory of the Tibetan Plateau to the Seventh Century A.D.: perspectives and research from China and the West since 1950 J. World Prehist. 18, 1-55.

An, C.B., Feng, Z., Tang, L., 2004. Environmental change and cultural response between 8000 and 4000 cal. yr BP in the western Loess Plateau, northwest China. J. Quat. Sci. 19, 529-535.

An, C.B., Tang, L., Barton, L., Chen, F.H., 2005. Climate change and cultural response around $4000 \mathrm{cal} \mathrm{yr} \mathrm{B.P.} \mathrm{in} \mathrm{the} \mathrm{western} \mathrm{part} \mathrm{of} \mathrm{the} \mathrm{Chinese} \mathrm{Loess} \mathrm{Plateau.} \mathrm{Quat.} \mathrm{Res.} \mathrm{63,}$ 347-352.

An, C.B., Dong, W., Li, H., Chen, Y., Barton, L., 2013. Correspondence regarding "Origin and spread of wheat in China," by Dodson, J.R., Li, X., Zhou, X., Zhao, K., Sun., Atahan, P. (2013). Quaternary Science Reviews 72, 108-111.

Anderson, R.L., 1994. Planting date effects on no-till Proso Millet. J. Prod. Agric. 7, 454-458.

Barton, L., 2009. Early Food Production in China's Western Loess Plateau, Anthropology. University of California, Davis, Davis, CA, (Unpublished PhD Dissertation).

Barton, L., 2014. A review of adaptation and invention during the spread of agriculture to southwest China, a PhD dissertation in the Department of Anthropology, Harvard University, by Jade d'Alpoim Guedes. Dissertation Reviews http:// dissertationreviews.org/spread-agriculture-southwest-china/ (published online May 12, 2014).

Barton, L., An, C.B., 2014. An evaluation of competing hypotheses for the early adoption of wheat in East Asia. World Archaeol. 46, 775-798.

Barton, L., Brantingham, P.J., Ji, D.X., 2007. Late Pleistocene climate change and Paleolithic cultural evolution in northern China: implications from the Last Glacial Maximum. In: Madsen, D.B., Gao, X., Chen, F.H. (Eds.), Late Quaternary Climate Change and Human Adaptation in Arid China. Elsevier, Amsterdam, pp. 105-128.

Barton, L., Morgan, C., Bettinger, R.L., 2009a. Harvests for the hunters: the origins of food production in arid northern China. SAA Archaeol. Rec. 9, 28-31.

Barton, L., Newsome, S.D., Chen, F.H., Hui, W., Guilderson, T.P., Bettinger, R.L., 2009b. Agricultural origins and the isotopic identity of domestication in northern China. Proc. Natl. Acad. Sci. 106, 5523-5528.

Beall, C.M., 2007. Two routes to functional adaptation: Tibetan and Andean high-altitude natives. Proc. Natl. Acad. Sci. 104, 8655-8660.

Beall, C.M., 2013. Human adaptability studies at high altitude: research designs and major concepts during fifty years of discovery. Am. J. Hum. Biol. 25, 141-147.

Beall, C.M., Song, K., Elston, R.C., Goldstein, M.C., 2004. Higher offspring survival among Tibetan women with high oxygen saturation genotypes residing at $4000 \mathrm{~m}$. Proc. Natl. Acad. Sci. 101, 14300-14304

Beall, C.M., Cavalleri, G.L., Deng, L., Elston, R.C., Gao, Y., Knight, J., Li, C., Li, J.C., Liang, Y., McCormack, M., Montgomery, H.E., Pan, H., Robbins, P.A., Shianna, K.V., Tam, S.C., Tsering, N., Veeramah, K.R., Wang, W., Wangdui, P., Weale, M.E., Xu, Y., Xu, Z., Yang, L., Zaman, M.J., Zeng, C., Zhang, L., Zhang, X., Zhaxi, P., Zheng, Y.T., 2010. Natural selection on EPAS1 (HIF2 $\alpha$ ) associated with low hemoglobin concentration in Tibetan highlanders. Proc. Natl. Acad. Sci. 107, 11459-11464.

Bettinger, R.L., 1991. Aboriginal occupation at high altitude: alpine villages in the White Mountains of Eastern California. Am. Anthropol. 93, 656-679.

Bettinger, R.L., Barton, L., Morgan, C., Chen, F., Wang, H., Guilderson, T.P., Ji, D., Zhang, D., 2010a. The transition to agriculture at Dadiwan, People's Republic of China. Curr. Anthropol. 51, 703-714.

Bettinger, R.L., Barton, L., Morgan, C.T., 2010b. The origins of food production in North China: a different kind of agricultural revolution. Evol. Anthropol. 19, 9-21.

Bigham, A.W., Lee, F.S., 2014. Human high-altitude adaptation: forward genetics meets the HIF pathway. Genes Dev. 28, 2189-2204.

Bigham, A.W., Bauchet, M., Pinto, D., Mao, Z., Akey, J.M., Mei, R., Scherer, S.W., Julian, C.G. Wilson, M.J., Herráez, D.L., Brutsaert, T., Parra, E.J., Moore, L.G., Shriver, M.D., 2010. Identifying signatures of natural selection in Tibetan and Andean populations using dense genome scan data. PLoS Genet. 6, e1001116.

Brantingham, P.J., Gao, X., 2006. Peopling of the northern Tibetan Plateau. World Archaeol. $38,387-414$

Brantingham, P.J., Olsen, J.W., Schaller, G.B., 2001. Lithic assemblages from the Chang Tang region, Northern Tibet. Antiquity 75, 319-327.

Brantingham, P.J., Ma, H., Olsen, J.W., Gao, X., Madsen, D.B., Rhode, D.E., 2003. Speculation on the timing and nature of Late Pleistocene hunter-gatherer colonization of the Tibetan Plateau. Chin. Sci. Bull. 48, 1510-1516.

Brantingham, P.J., Gao, X., Olsen, J.W., Ma, H., Rhode, D., Zhang, H., Madsen, D.B., 2007. A short chronology for the peopling of the Tibetan Plateau. In: Madsen, D.B., Gao, X., Chen, F.H. (Eds.), Late Quaternary Climate Change and Human Adaptation in Arid China. Elsevier, Amsterdam, pp. 129-150.

Brantingham, P.J., Xing, G., Madsen, D.B., Rhode, D., Perreault, C., van der Woerd, J., Olsen, J.W., 2013. Late occupation of the high-elevation northern Tibetan Plateau based on cosmogenic, luminescence, and radiocarbon ages. Geoarchaeology 28, 413-431.

Chen, J., 2007. Boxi, Yingpanshan, and Shawudu. The cultural development of Neolithic cultures in the Upper Min River. Kaogu Yu Wenwu 5, 65-70.

Chen, J., Chen, X., Fan, Y., 2004. A survey of the investigation of the Neolithic cultural relics located on the upper Minjiang River, and an archaeological excavation of Mount Yingpanshan. J. Aba Teach. Coll. 21, 25-28.

Chen, F., Dong, G., Zhang, D., Liu, X., Jia, X., An, C.B., Ma, M., Xie, Y.W., Barton, L., Ren, X.Y., Zhao, Z., Wu, X.H., Jones, M.K., 2015. Agriculture facilitated permanent human occupation of the Tibetan plateau. Science 347, 248-250.

d'Alpoim Guedes, J., 2013. Adaptation and Invention During the Spread of Agriculture to Southwest China, Anthropology. Harvard University, Cambridge, MA (Unpublished PhD Dissertation)

d'Alpoim Guedes, J., 2015. Rethinking the spread of agriculture to the Tibetan Plateau. The Holocene 25, 1498-1510.

d'Alpoim Guedes, J., Butler, E.E., 2014. Modeling constraints on the spread of agriculture to southwest China with thermal niche models. Quat. Int. 349, 29-41.

d'Alpoim Guedes, J., Lu, H., Li, Y., Spengler, R.N., Wu, X., Aldenderfer, M.S., 2013. Moving agriculture onto the Tibetan plateau: the archaeobotanical evidence. Archaeol. Anthropol. Sci. 6, 255-269.

d'Alpoim Guedes, J.A., Lu, H., Hein, A.M., Schmidt, A.H., 2015. Early evidence for the use of wheat and barley as staple crops on the margins of the Tibetan Plateau. Proc. Natl. Acad. Sci. 112, 5625-5630.

Dodson, J.R., Li, X., Zhou, X., Zhao, K., Sun, N., Atahan, P., 2013. Origin and spread of wheat in China. Quat. Sci. Rev. 72, 108-111.

Dodson, J., Dodson, E., Banati, R., Li, X., Atahan, P., Hu, S., Middleton, R.J., Zhou, X., Nan, S., 2014. Oldest directly dated remains of sheep in China. Sci. Rep. 4 http://dx.doi.org/10. 1038/srep07170.

Drennan, R.D., Berrey, C.A., Peterson, C.E., 2015. Regional Settlement Demography in Archaeology. Eliot Werner Publications, Inc, Clinton Corners, NY.

Elston, R.G., Brantingham, P.J., 2002. Microlithic technology in Northern Asia: a riskminimizing strategy of the Late Paleolithic and Early Holocene. In: Elston, R.G., Kuhn, S.L. (Eds.), Thinking Small: Global Perspectives on Microlithization. American Anthropological Association, Washington D.C., pp. 103-116. 
Elston, R.G., Dong, G., Zhang, D., 2011. Late Pleistocene intensification technologies in Northern China. Quat. Int. 242, 401-415.

Flad, R., Li, S., Wu, X., Zhao, Z., 2010. Early wheat in China: results from new studies at Donghuishan in the Hexi Corridor. The Holocene 20, 955-965.

Goebel, T., 1999. Pleistocene human colonization of Siberia and the peopling of the Americas: an ecological approach. Evol. Anthropol. 8, 208-227.

Hazarika, M., 2016. Tracing post-Pleistocene human movements and cultural connections of the eastern Himalayan region with the Tibetan Plateau. Archaeol. Res. Asia 5, 44-53 (in this issue).

Hein, A.M., 2015. Environmental preconditions and human response: subsistence practices at prehistoric settlement sites in the Liangshan Region, Southwest China. Asian Archaeol. 3, 39-94

Hoffecker, J.F., 2005. A Prehistory of the North: Human Settlement of the Higher Latitudes. Rutgers University Press, New Brunswick, NJ.

Hornbein, T.F., Schoene, R.B., 2001. High Altitude: An Exploration of Human Adaptation. Marcel Dekker, New York.

Hou, G., Ma, Z.,.E...C., Zhang, W., Wei, H., 2016. Plant utilization at the Jiangxigou site during the middle Holocene. Archaeol. Res. Asia 5, 54-62 (in this issue).

Huang, W., 1994. The prehistoric human occupation of the Qinghai-Xizang Plateau. Göttinger Geograp. Abh. 95, 201-219.

Huerta-Sanchez, E., Jin, X., Asan, B.,.Z., Peter, B.M., Vinckenbosch, N., Liang, Y., Yi, X., He, M., Somel, M., Ni, P., Wang, B., Ou, X., Huasang, Luosang, J., Cuo, Z.X.P., Li, K., Gao, G., Yin, Y., Wang, W., Zhang, X., Xu, X., Yang, H., Li, Y., Wang, J., Wang, J., Nielsen, R., 2014. Altitude adaptation in Tibetans caused by introgression of Denisovan-like DNA. Nature 512, 194-197.

Jiang, Z., 2007. Anning he liuye kaoguxue wenhua shixi (Chronology of the archaeological cultures of the Anning River Valley). Sichuan Wenwu (Sichuan Cult. Relics) 3-11.

Kamkar, B., Koocheki, A., Nassiri Mahallati, M., Rezvani Moghaddam, P., 2006. Cardinal temperatures for germination in three millet species (Panicum miliaceum, Pennisetum glaucum and Setaria italica). Asian J. Plant Sci. 5, 316-319.

Li, S., Mo, D., 2004. Donghuishan yizhi tanhua xiaomai niandaikao (Considering the dating of carbonized wheat at the site of Donghuishan). Kaogu Wenwu (Archaeol. Cult. Relics) 51-60.

Li, X., Dodson, J., Zhou, X., Zhang, H., Masutomoto, R., 2007a. Early cultivated wheat and broadening of agriculture in Neolithic China. The Holocene 17, 555-560.

Li, X., Zhou, X., Zhou, J., Dodson, J., Zhang, H., Shang, X., 2007b. The earliest archaeobiological evidence of the broadening agriculture in China recorded at Xishanping site in Gansu Province. Sci. China (Ser. D) 50, 1707-1714.

Liu, P., Wei, D., 1974. Sichuan Sheng Hanyuan Xian dashu gonshe Shizishan faxian xinshiqi shidai yizhi (Discovery of a Neolithic period site in teh Dashu Commune in Shizishan, Hanyuan County, Sichuan). Wenwu (Cult. Relics) 1974, 91.

$\mathrm{Lu}, \mathrm{H}$., 2016. Colonization of the Tibetan Plateau, permanent settlement, and the spread of wheat: reflection on current debates on the prehistoric archaeology of the Tibetan Plateau. Archaeol. Res. Asia 5, 12-15 (in this issue).

Madsen, D.B., 2016. Conceptualizing the Tibetan Plateau: environmental constraints on the peopling of the "Third Pole". Archaeol. Res. Asia 5, 24-32 (in this issue).

Madsen, D.B., Ma, H., Brantingham, P.J., Gao, X., Rhode, D., Zhang, H., Olsen, J.W., 2006. The late Upper Paleolithic occupation of the northern Tibetan Plateau margin. J. Archaeol. Sci. 33, 1433-1444

Miehe, G., Miehe, S., Kaiser, K., Reudenbach, C., Behrendes, L., Duo, L., Schlütz, F., 2009. How old is pastoralism in Tibet? An ecological approach to the making of a Tibetan landscape. Palaeogeogr. Palaeoclimatol. Palaeoecol. 276, 130-147.

Miehe, G., Miehe, S., Böhner, J., Kaiser, K., Hensen, I., Madsen, D.B., Liu, J.Q., Opgenoorth, L., 2014. How old is the human footprint in the world's largest alpine ecosystem? A review of multiproxy records from the Tibetan Plateau from the ecologists' viewpoint. Quat. Sci. Rev. 86, 190-209.

Morgan, C., Barton, L., Bettinger, R.L., Chen, F., Zhang, D., 2011. Glacial cycles and Palaeolithic adaptive variability on China's Western Loess Plateau. Antiquity 85, 365-379.

Morgan, C., Losey, A., Adams, R., 2012. High-altitude hunter-gatherer residential occupations in Wyoming's Wind River Range. N. Am. Archaeol. 33, 35-79.

Neme, G., 2016. El Indígeno and high-altitude human occupation in the southern Andes. Lat. Am. Archaeol. (in press).

Niermeyer, S., Yang, P., Shanmina, D., Zhuang, J., Moore, L.G., 1995. Arterial oxygen saturation in Tibetan and Han infants born in Lhasa, Tibet. N. Engl. J. Med. 333, 1248-1252.

Niermeyer, S., Zamdio, S., Moore, L.G., 2001. The people. In: Hornbein, T., Schoenel, R. (Eds.), High Altitude: An Exploration of Human Adaptation. Marcel Dekker, New York, pp. 42-100.

Peng, Y., Yang, Z., Zhang, H., Cui, C., Qi, X., Luo, X., Tao, X., Wu, T., Ouzhuluobu, B., Ciwangsangbu, D., Chen, H., Shi, H., Su, B., 2011. Genetic variations in Tibetan populations and high-altitude adaptation at the Himalayas. Mol. Biol. Evol. 28, 1075-1081.

Qi, X., Cui, C., Peng, Y., Zhang, X., Yang, Z., Zhong, H., Zhang, H., Xiang, K., Cao, X., Wang, Y., Ouzhuluobu, Basang, Ciwangsangbu, Bianba, Gonggalanzi, Wu, T., Chen, H., Shi, H., Su, B., 2013. Genetic evidence of Paleolithic colonization and Neolithic expansion of modern humans on the Tibetan Plateau. Mol. Biol. Evol. 30, 1761-1778.

Qian, Y., Qian, B., Su, B., Yu, J., Ke, Y., Chu, Z., Shi, L., Lu, D., Chu, J., Jin, L., 2000. Multiple origins of Tibetan Y chromosomes. Hum. Genet. 106, 453-454.

Raghavan, M., DeGiorgio, M., Albrechtsen, A., Moltke, I., Skoglund, P., Korneliussen, T.S. Grønnow, B., Appelt, M., Gulløv, H.C., Friesen, T.M., Fitzhugh, W., Malmström, H., Rasmussen, S., Olsen, J., Melchior, L., Fuller, B.T., Fahrni, S.M., Stafford, T., Grimes, V., Renouf, M.A.P., Cybulski, J., Lynnerup, N., Lahr, M.M., Britton, K., Knecht, R., Arneborg, J., Metspalu, M., Cornejo, O.E., Malaspinas, A.-S., Wang, Y., Rasmussen, M., Raghavan, V., Hansen, T.V.O., Khusnutdinova, E., Pierre, T., Dneprovsky, K., Andreasen, C., Lange, H., Hayes, M.G., Coltrain, J., Spitsyn, V.A., Götherström, A. Orlando, L., Kivisild, T., Villems, R., Crawford, M.H., Nielsen, F.C., Dissing, J.,
Heinemeier, J., Meldgaard, M., Bustamante, C., O'Rourke, D.H., Jakobsson, M., Gilbert M.T.P., Nielsen, R., Willerslev, E., 2014. The genetic prehistory of the New World Arctic. Science 345 .

Rasmussen, M., Anzick, S.L., Waters, M.R., Skoglund, P., DeGiorgio, M., Stafford Jr., T.W., Rasmussen, S., Moltke, I., Albrechtsen, A., Doyle, S.M., Poznik, G.D., Gudmundsdottir, V., Yadav, R., Malaspinas, A.-S., V, S.S.W., Allentoft, M.E., Cornejo, O.E., Tambets, K. Eriksson, A., Heintzman, P.D., Karmin, M., Korneliussen, T.S., Meltzer, D.J., Pierre, T.L., Stenderup, J., Saag, L., Warmuth, V.M., Lopes, M.C., Malhi, R.S., Brunak, S. Sicheritz-Ponten, T., Barnes, I., Collins, M., Orlando, L., Balloux, F., Manica, A., Gupta R., Metspalu, M., Bustamante, C.D., Jakobsson, M., Nielsen, R., Willerslev, E., 2014 The genome of a Late Pleistocene human from a Clovis burial site in western Montana. Nature 506, 225-229.

Rasmussen, M., Sikora, M., Albrechtsen, A., Korneliussen, T.S., Moreno-Mayar, J.V., Poznik, G.D., Zollikofer, C.P.E., Ponce de Leon, M.S., Allentoft, M.E., Moltke, I., Jonsson, H., Valdiosera, C., Malhi, R.S., Orlando, L., Bustamante, C.D., Stafford Jr., T.W., Meltzer, D.J., Nielsen, R., Willerslev, E., 2015. The ancestry and affiliations of Kennewick Man. Nature 523, 455-458.

Rhode, D., 2016. A biogeographic perspective on early human colonization of the Tibetan Plateau. Archaeol. Res. Asia 5, 33-43 (in this issue).

Rhode, D., Madsen, D.B., Brantingham, P.J., Dargye, T., 2007a. Yaks, yak dung, and prehistoric human habitation of the Tibetan Plateau. In: Madsen, D.B., Gao, X., Chen, F.H. (Eds.), Late Quaternary Climate Change and Human Adaptation in Arid China. Elsevier, Amsterdam, pp. 205-224.

Rhode, D., Zhang, H., Madsen, D.B., Gao, X., Brantingham, P.J., Ma, H., Olsen, J.W., 2007b. Epipaleolithic/early Neolithic settlements at Qinghai Lake, western China. J. Archaeol. Sci. 34, 600-612.

Richerson, P.J., Boyd, R., Henrich, J., 2010. Gene-culture coevolution in the age of genomics. Proc. Natl. Acad. Sci. 107, 8985-8992.

Sagart, L., 2005. Sino-Tibetan-Austronesian: an updated and improved argument. In: Sagart, L., Blench, R., Sanchez-Mazas, A. (Eds.), The Peopling of East Asia: Putting Together Archaeology, Linguistics and Genetics. RoutledgeCurzon, London, pp. 161-176.

Scheinfeldt, L.B., Tishkoff, S.A., 2013. Recent human adaptation: genomic approaches, interpretation and insights. Nat. Rev. Genet. 14, 692-702.

Simonson, T.S., 2015. Altitude adaptation: a glimpse through various lenses. High Alt Med. Biol. 16, 125-137.

Simonson, T.S., Yang, Y., Huff, C.D., Yun, H., Qin, G., Witherspoon, D.J., Bai, Z., Lorenzo, F.R., Xing, J., Jorde, L.B., Prchal, J.T., Ge, R., 2010. Genetic evidence for high-altitude adaptation in Tibet. Science 329, 72-75.

Simonson, T.S., McClain, D.A., Jorde, L.B., Prchal, J.T., 2012. Genetic determinants of tibetan high-altitude adaptation. Hum. Genet. 131, 527-533.

Storz, J.F., Scott, G.R., Cheviron, Z.A., 2010. Phenotypic plasticity and genetic adaptation to high-altitude hypoxia in vertebrates. J. Exp. Biol. 213.

Storz, J.F., Opazo, J.C., Hoffmann, F.G., 2013. Gene duplication, genome duplication, and the functional diversification of vertebrate globins. Mol. Phylogenet. Evol $66,469-478$

Su, B., Xiao, C., Deka, R., Seielstad, M.T., Kangwanpont, D., Xiao, J., Lu, D., Underhill, P., Cavalli-Sforza, L.L., Chakraborty, R., Jin, L., 2000. Y chromosome haplotypes reveal prehistorical migrations to the Himalayas. Hum. Genet. 107, 582-590.

Tang, H., Hare, J.M., 1995. Lithic tool industries and the earliest occupation of the QinghaiTibetan Plateau. Artefact 18, 3-11.

Tong, E., 1985. Xizang kaogu zongshu (summary of the archaeology of Tibet). Wenwu (Cult. Relics) 9, 9-19.

Torroni, A., Miller, J., Moore, L., Zamudio, Z., Zhuang, J., Droma, T., Wallace, D., 1994 Mitochondrial DNA analysis in Tibet - implications for the origin of the Tibetan population and its adaptation to high altitude. Am. J. Phys. Anthropol. 92, 189-199.

van Driem, G., 2002. Tibeto-Burman phylogeny and prehistory: languages, material culture, and genes. In: Bellwood, P., Renfrew, C. (Eds.), Examining the Farming/Language Dispersal Hypothesis. McDonald Institute for Archaeological Research, Cambridge, pp. 233-249.

van Driem, G., 2005. Tibeto-Burman vs Indo-Chinese. In: Sagart, L., Blench, R., SanchezMazas, A. (Eds.), The Peopling of East Asia: Putting Together Archaeology, Linguistics and Genetics. RoutledgeCurzon, London, pp. 81-106.

Wang, B., Zhang, Y.B., Zhang, F., Lin, H., Wang, X., Wan, N., Ye, Z., Weng, H., Zhang, L., Li, X. Yan, J., Wang, P., Wu, T., Cheng, L., Wang, J., Wang, D.M., Ma, X., Yu, J., 2011. On the origin of Tibetans and their genetic basis in adapating to high-altitude environments. PLoS One 6, e17002.

Wenwuju, Guojia, 2011. Zhongguo Wenwu Dituji: Gansu (An Atlas of Chinese Cultural Relics in Gansu). In: Editorial Board, The National Bureau of Cultural Relics (Ed.), An Atlas of Chinese Cultural Relics. Xi'an ditu chubanshe (Xi'an Map Press), Xi'an.

Xizang and Sichuan (Xizang Zizhiqu Wenwu Gaunli Weiyuanhui \& Sichuan Daxue Lishixi), 1985i. Changdu Karuo (Karuo in Changdu). Wensu Chubanshe, Beijing.

Xu, S., Li, S., Yang, Y., Tan, J., Lou, H., Jin, W., Yang, L., Pan, X., Wang, J., Shen, Y., Wu, B., Wang, H., Jin, L., 2011. A genome-wide search for signals of high-altitude adaptation in Tibetans. Mol. Biol. Evol. 28, 1003-1011.

Yi, X., Liang, Y., Huerta-Sanchez, E., Jin, X., Cuo, Z.X.P., Pool, J.E., Xu, X., Jiang, H. Vinckenbosch, N., Korneliussen, T.S., Zheng, H., Liu, T., He, W., Li, K., Luo, R., Nie, X. Wu, H., Zhao, M., Cao, H., Zou, J., Shan, Y., Li, S., Yang, Q., Asan, Ni, P., Tian, G., Xu, J. Liu, X., Jiang, T., Wu, R., Zhou, G., Tang, M., Qin, J., Wang, T., Feng, S., Li, G., Huasang, Luosang, J., Wang, W., Chen, F., Wang, Y., Zheng, X., Li, Z., Bianba, Z., Yang, G., Wang, X., Tang, S., Gao, G., Chen, Y., Luo, Z., Gusang, L., Cao, Z., Zhang, Q., Ouyang, W., Ren, X., Liang, H., Zheng, H., Huang, Y., Li, J., Bolund, L., Kristiansen, K., Li, Y., Zhang, Y., Zhang, X., Li, R., Li, S., Yang, H., Nielsen, R., Wang, J., Wang, J., 2010. Sequencing of 50 human exomes reveals adaptation to high altitude. Science 329, 75-78. 
Yi, M., Barton, L., Morgan, C., Liu, D., Chen, F., Zhang, Y., Pei, S., Guan, Y., Wang, H., Gao, X., Bettinger, R.L., 2013. Microblade technology and the rise of serial specialists in northcentral China. J. Anthropol. Archaeol. 32, 212-223.

Zhang, D.D., Li, S.H., 2002. Optical dating of Tibetan human hand- and footprints: an implication for the palaeoenvironment of the last glaciation of the Tibetan Plateau. Geophys. Res. Lett. 29, 16,11-16,13.
Zhao, M., Kong, Q.-P., Wang, H.-W., Peng, M.-S., Xie, X.-D., Wang, W.-Z., Jiayang, D...J.-G., Cai, M.-C., Zhao, S.-N., Cidanpingcuo, T.,.Y.-Q..., Wu, S.-F., Yao, Y.-G., Bandelt, H.-J., Zhang, Y.-P., 2009. Mitochondrial genome evidence reveals successful Late Paleolithic settlement on the Tibetan Plateau. Proc. Natl. Acad. Sci. 106, 21230-21235. 